\title{
O PROJETO DE BRINQUEDOS PARA O UNIVERSO INFANTIL: EXPERIÊNCIAS DO DESENHO INDUSTRIAL EM PARCERIA COM A TERAPIA OCUPACIONAL
}

\section{THE DESIGN OF TOYS FOR THE UNIVERSE FOR CHILDREN: EXPERIENCES OF INDUSTRIAL DESIGN IN PARTNERSHIP WITH OCCUPATIONAL THERAPY}

\author{
Roseane Santos da Silva1, M. Sc.; Fabiane Vieira Romano², D. Sc.; Amara Lucia Holanda Battistel ${ }^{3}$, D. \\ Sc.; Catherine Rosa ${ }^{4}$, Graduada. \\ (1),UFSM, e-mail: roseanedoro@yahoo.com.br
}

(2),UFSM; e-mail: fabiromano@gmail.com (3)UFSM; e-mail: amarahb@gmail.com

(4) UFSM; e-mail: catherine.r.rosa@gmail.com

design de produto, interdisciplinar, crianças.

\begin{abstract}
Existem muitas demandas relacionadas ao projeto de produtos para o universo infantil. Os brinquedos em especial podem ser fonte de estímulo ao desenvolvimento em diferentes fases da infância. No caso de crianças em internamento hospitalar, os brinquedos e produtos que exploram a ludicidade podem promover melhorias nos quadros dos tratamentos através da construção de um ambiente favorável. O objetivo desse artigo é o de mostrar práticas do desenvolvimento do projeto de produtos variados para o público de crianças de diferentes faixas etárias realizadas na parceria dos cursos de Desenho Industrial e Terapia Ocupacional. Serão apresentados os resultados alcançados ao longo da realização do projeto de pesquisa Estimular Brincando bem como de trabalhos de conclusões de curso desenvolvidos a partir dessa parceria interdisicplinar entre o Desenho Industrial e a Terapia Ocupacional.
\end{abstract}

Product design, interdisciplinary, children.

There are many demands related to the design of products for the universe of children. Toys in particular can be asource of developmental stimuli at different stages of childhood. In the case of in-hospital children, toys and products that exploit playfulness can promote improvements in treatment settings by building a favorable environment. The objective of this article is to show practices of the development of the project of varied products for the public of children of different age groups carried out in the partnership of the courses of Industrial Desig and Occupational Therapy. The results will be presented during the realization of the project "Estimular Brincando" as well as of work of course conclusions developed from this interdisciplinary partnership between the Industrial Design and Occupational Therapy.

Realização:



\section{$16^{\circ}$ \\ ERGODESIGN USIHC CINAHPA}

\section{Introdução}

Desenho Industrial é uma profissão de caráter projetual desenvolvida a partir de um processo contínuo de tomada de decisões tendo como ponto de partida um problema a ser resolvido. É um campo que abrange uma gama de subáreas onde o trabalho se torna mais ou menos complexo de acordo com o produto a ser desenvolvido. $\mathrm{O}$ curso de terapia ocupacional é uma das áreas com as quais o desenho industrial pode estabelecer conexões interdisciplinares a fim de favorecer o desenvolvimento e soluções no projeto de produtos.

Nesse sentido, muito pode ser desenvolvido em produtos para o universo infantil. Os produtos utilizados nessa fase da vida podem ser utilizados como fontes de estímulo e aprendizado. Assim o presente artigo tem como objetivo explanar sobre as práticas realizadas a partir da parceria entre essas duas áreas de atuação.

O Projeto Estimular Brincando do Curso de Desenho Industrial tem uma trajetória consagrada na criação de produtos para o universo infantil que favoreçam o desenvolvimento infantil e o brincar. O curso de Terapia Ocupacional desenvolve ações de ensino, pesquisa e extensão por meio do Projeto Cuidado e Atenção às Crianças e Adolescentes em Tratamento Oncológico - CAACTO, no Centro de Convivência Turma do Ique e no Centro de Tratamento da Criança e do Adolescente com Câncer do Hospital Universitário de Santa Maria. Motivados pelo desejo comum de transformar o ambiente de modo a proporcionar uma melhor qualidade de vida e maximizar as potencialidades da criança e seu vir a ser no mundo, estabelece-se a parceria entre os cursos de Desenho Industrial e Terapia Ocupacional.

\section{0 brincar e o universo infantil}

O brincar é fruto de uma aprendizagem social e humana fundamental para o processo de interação da criança com o meio físico e social. Inicialmente $\mathrm{o}$ adulto funciona como um mediador entre a criança e o mundo físico e social e as relações $16^{\circ}$ Ergodesign - Congresso Internacional de Ergonomia e Usabilidade de Interfaces Humano Tecnológica: Produto, Informações Ambientes Construídos e Transporte

$16^{\circ}$ USIHC - Congresso Internacional de Ergonomia e Usabilidade de Interfaces Humano Computador

CINAHPA | 2017 - Congresso Internacional de Ambientes Hipermídia para Aprendizagem. afetivas estabelecidas entre eles potencializam o exercício das funções sensoriais primitivas, precursoras do brincar, das atividades psicomotoras e do surgimento da linguagem.

O desenvolvimento do brincar ocorre por meio de uma sequência evolutiva articulada ao desenvolvimento neuropsicomotor, havendo uma clara relação entre eles. Inicialmente a partir do repertório do desenvolvimento sensório-motor a criança explora o próprio corpo e os objetos do mundo físico que a rodeia, experimenta as primeiras relações sociais, inicialmente com as pessoas mais próximas. Essa interação tem um caráter formador, organizador e estruturante, e é a base em que se formam as construções cognitivas da criança.

Nessa relação, o adulto propicia diferentes situações em que estimula e direciona a atividade da criança. Nos dois primeiros anos de vida a criança se envolve em jogos sensórios-motores por meio dos quais manipulam objetos e o mundo físico e social ao seu redor que servem para organizar o ato motor e conceder à criança uma nova forma de atividade exploradora. $\mathrm{O}$ desenvolvimento sensório-motor funciona como exercício dos processos essenciais para o desenvolvimento ulterior, principalmente o desenvolvimento das coordenações vasomotoras que serve de alicerce para outros tipos de atividade (ELKONIN, 1985).

As ações com objetos orientadas pelo adulto vão lenta e progressivamente se ampliando e abraçando uma série de atividades diferentes. Com o surgimento da linguagem inicia-se o desenvolvimento da capacidade de imitação, seguida do desenvolvimento da imaginação e simbolização, até que, por volta dos 3,4 anos de idade surge o jogo simbólico e com ele as ações lúdicas começam a refletir a lógica das relações entre as pessoas. Por meio da imaginação a criança assimila o universo do mundo adulto, os papéis socialmente elaborados e conceitos morais, os quais no futuro servirão como parâmetro para os níveis de ação real e para seus padrões de moralidade. Por meio do brincar a criança assimila a realidade, se socializa e se apropria da cultura, o
Realização:

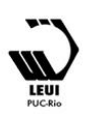




\section{$16^{\circ}$ \\ ERGODESIGN USIHC CINAHPA}

que faz da brincadeira uma importante fonte de desenvolvimento intelectual e da personalidade infantil (ELKONIN 198).

Nascido da necessidade de se comunicar com os adultos e de agir sobre os objetos e o mundo mais amplo destes, o jogo simbólico proporciona por meio do uso da imaginação, a satisfação dessas necessidades, ao mesmo tempo em que cria uma zona de desenvolvimento potencial, posto que, segundo VYGOTSKY (1989), no brinquedo a criança sempre se comporta de modo mais avançado em relação ao estágio de desenvolvimento em que se encontra. Dessa forma, o brinquedo é uma importante fonte subsidiária e suplementar do desenvolvimento.

Na sequencia evolutiva do brincar surge entre os 6 , 7 anos de idade o jogo de regras, nessa fase a criança aprende a se submeter às regras do jogo, e isto indica um novo e mais avançado estágio de desenvolvimento. Este tipo de jogo contribui o desenvolvimento do pensamento abstrato; socialização da criança; submissão às regras sociais; desenvolvimento da autonomia; aprendizagem para realizar atividades em grupos; regular o próprio comportamento; tolerar frustração, enfim a reger seu comportamento e atitudes diante dos grupos sociais.

O brincar, pois, perpassa toda a vida da criança estimulando e gerando desenvolvimento de acordo com as peculiaridades inerentes a cada fase do desenvolvimento infantil. Pode-se dizer que na infância, viver, crescer e aprender são processos intimamente relacionados com a atividade lúdica. Diante dessas características e potencialidades o brincar este torna-se, nas mãos do terapeuta ocupacional, um veículo bastante utilizado para fins de avaliação do desenvolvimento infantil e do desempenho ocupacional da criança, bem como para a intervenção terapêutica, seja na prevenção de agravos, na promoção ou recuperação da saúde.

Cabe falar também sobre a hospitalização ser um momento marcante e, na maioria das vezes, difícil para qualquer indivíduo. Quando se trata de crianças e adolescentes as dificuldades multiplicam-se. Pelas peculiaridades que lhe são $16^{\circ}$ Ergodesign - Congresso Internacional de Ergonomia e Usabilidade de Interfaces Humano Tecnológica: Produto, Informações Ambientes Construídos e Transporte

$16^{\circ}$ USIHC - Congresso Internacional de Ergonomia e Usabilidade de Interfaces Humano Computador

CINAHPA | 2017 - Congresso Internacional de Ambientes Hipermídia para Aprendizagem.

próprias, elas não têm condições de assimilar o processo de hospitalização seguindo o princípio de realidade com o qual o adulto opera, gerando, assim, fantasias muitas vezes assustadoras, tornando o processo ainda mais difícil.

A díade brincar e saúde tem se mostrado eficiente como estratégia multiprofissional na prevenção, manutenção e recuperação física e emocional do indivíduo, o que tem levado diversos profissionais da saúde a recorrer a este recurso como estratégia terapêutica. Além disso, é comum que os procedimentos sejam administrados sem que se explique à criança o como e o porquê. Seu corpo muitas vezes é controlado e manipulado pela equipe de saúde antes mesmo que se estabeleça uma relação pessoal e de confiança com a criança.

Diante desta constatação, é essencial que seja possibilitado um contexto que favoreça a expressão e elaboração de sentimentos de medo, estranheza, desconfiança, insegurança, entre outros, em um clima de confiança e ajuda, para viabilizar a compreensão, pela criança, dos sentimentos e atitudes que emergem durante a hospitalização. Isto pode ser melhorado através da implantação de medidas que possibilitem diferentes formas de expressividade: corporal, plástica e lúdica, indo além das verbalizações, pois até mesmo "as crianças maiores que possuem o recurso da fala, não têm na linguagem verbal seu principal meio de compreensão, priorizando o brincar como linguagem fundamental da elaboração da expressão do mundo" (ROZA, 1997, p.169).

Assim sendo, a atividade lúdica funciona como um meio, um recurso para elaboração e associação das situações limites que a doença e a hospitalização impõem às crianças e seus familiares. Alguns pesquisadores Roza (1997), Winnicott (1975), Freud (1969) e Kudo (1994) têm demonstrado os efeitos terapêuticos e profiláticos da atividade lúdica, como um aliado nos processos de diagnóstico, adaptação, redução da dor, promotor da socialização da criança hospitalizada; servindo como medida para o restabelecimento físico, psíquico e cognitivo dos pacientes. Além de possibilitar a continuidade do desenvolvimento emocional, afetivo, motor e cognitivo, de modo
Realização:

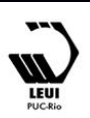




\section{$16^{\circ}$ \\ ERGODESIGN USIHC CINAHPA}

que o hospital não signifique um momento de interrupção no curso normal de desenvolvimento da criança e do adolescente.

\section{Práticas de desenvolvimento de produtos para o universo infantil}

\subsection{O PROJETO DE PESQUISA ESTIMULAR BRINCANDO}

O projeto, de pesquisa e extensão, originadas no Curso de Desenho Industrial da UFSM -

"Estimular brincando...", teve inicio em 2008, e visa o desenvolvimento e/ou adaptação de brinquedos de baixa complexidade, a partir do reconhecimento de estímulos que favoreçam o desenvolvimento infantil e o brincar, buscando sempre através de necessidades reais, beneficiar a comunidade local.

Em um primeiro momento neste projeto foi realizado um levantamento de informações através de pesquisa bibliográfica sobre a importância do brincar na infância, o papel da estimulação motora e sensorial em crianças e indivíduos com idade mental de 2 a 6 anos, e o uso do design para a promoção da inclusão. Além disso, foram observadas as formas de interação de indivíduos nessa faixa etária com brinquedos de baixa complexidade, com o intuito de identificar características favoráveis à estimulação. Ao longo do processo, o trabalho buscou um envolvimento transdisciplinar com educadores especiais, pedagogos e outras áreas, a fim de detectar problemas nos brinquedos existentes no mercado e levantar possíveis sugestões de novas configurações para esses produtos. Alguns brinquedos foram desenvolvidos tais como: tapete sensorial, livro das formas geométricas, brinquedos com peças de encaixe, entre outros (Figura 1). $16^{\circ}$ Ergodesign - Congresso Internacional de Ergonomia e Usabilidade de Interfaces Humano Tecnológica: Produto, Informações Ambientes Construídos e Transporte

$16^{\circ}$ USIHC - Congresso Internacional de Ergonomia e Usabilidade de Interfaces Humano Computador

CINAHPA | 2017 - Congresso Internacional de Ambientes Hipermídia para Aprendizagem.


Figura 1: Brinquedos produzidos nos primeiros resultados do Projeto Estimular Brincando. Fonte: autores.

Esses primeiros brinquedos foram expostos na Exposição do Projeto Estimular brincando ocorrido no ano de 2010 conforme mostra a Figura 2. 




$16^{\circ}$ Ergodesign - Congresso Internacional de Ergonomia e Usabilidade de Interfaces Humano Tecnológica: Produto, Informações Ambientes Construídos e Transporte

$16^{\circ}$ USIHC - Congresso Internacional de Ergonomia e Usabilidade de Interfaces Humano Computador

CINAHPA | 2017 - Congresso Internacional de Ambientes Hipermídia para Aprendizagem.



Figura 2: Crianças interagindo com os brinquedos na Exposição do Projeto Estimular Brincando...

Cabe ressaltar também três destes brinquedos desenvolvidos têm registro de desenho industrial junto ao INPI (Instituto Nacional da Propriedade Intelectual). Os exemplares dos brinquedos produzidos foram doados para a Escola Antônio Franscisco Lisboa localizada na cidade de Santa Maria.

\subsection{PRÁTICAS PARA PROMOÇÃO DA SAÚDE HOSPITALAR NA INFÂNCIA}

A partir de 2010, visando dar continuidade ao projeto Estimular brincando e atender às novas demandas, a Terapia Ocupacional passou a integrar a equipe. E, em 2011 profissionais da Turma do Ique - uma iniciativa Centro de Tratamento da Criança e do Adolescente com Câncer do Hospital Universitário de Santa Maria, que busca auxiliar, tanto os pacientes quanto os familiares, no decorrer do tratamento - aderiram ao grupo com o propósito de desenvolver produtos lúdico-educativos para serem utilizados por crianças e adolescentes em tratamento hemato-oncológico.

Os produtos foram elaborados a partir do conhecimento da realidade e compreensão das necessidades que envolvem o público atendido. A comunidade acadêmica foi se apropriando das peculiaridades que envolvem o cotidiano das crianças, adolescentes e seus familiares e cuidadores. Os produtos desenvolvidos visaram estimular trocas de experiências e vivencias entre os pacientes assim como trabalhar a autoestima e autonomia dos mesmos em relação ao seu processo de adoecimento e tratamento. Assim, com este olhar chegou-se a produtos que beneficiam crianças e adolescentes em tratamento hematooncológico, contribuindo para a compreensão do processo de adoecimento e recuperação e, por conseguinte, facilitando os procedimentos terapêuticos e a atuação dos profissionais de saúde, entre eles destaca-se: diário com adesivos; calendário com adesivos; faixa com bottons; cabelinho; dedoches e fantoches; teatrinho; mural; figuras para colorir (Figura 3)



Figura 3: Imagens do Kit, Calendário, dedoches bottons desenvolvidos. Fonte: Autores.

Em 2013, o projeto atendendo a novas demandas do CTCriac - repensar os quartos de internação, a sala de quimioterapia e sala de recreação - todos ambientes destinados a crianças e a adolescentes com câncer -, chegou a contar com 15 alunos de graduação trabalhando: 6 de Desenho Industrial Projeto de Produto; 3 de Desenho Industrial Programação Visual; 1 da Arquitetura; e 5 da Terapia Ocupacional.

Destacam-se desta fase dois trabalhos de conclusão de curso do Desenho Industrial - Projeto de Produto: o carrinho CIRCO e a mesa MIMO, ambos produtos com registro de Desenho Industrial junto ao INPI.

\subsubsection{CARRINHO CIRCO}

O presente trabalho de conclusão de curso, apoiado
Realização:
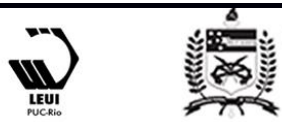


\section{$16^{\circ}$ \\ ERGODESIGN USIHC CINAHPA}

na necessidade da atuação do designer no âmbito social, apresenta um estudo de caso realizado no Ambulatório de Quimioterapia do Hospital Universitário de Santa Maria (HUSM), reunindo informações acerca do câncer, do tratamento quimioterápico e, principalmente, da carência de meios de entretenimento das crianças, enquanto são submetidas a esse tratamento. Com a proposta do desenvolvimento de um produto que, através da atividade lúdica, possa atenuar o sofrimento causado pelo tratamento oncológico infantil, foram realizadas observações in loco e entrevistas com a equipe médica, bem como, a investigação por parte das graduandas do curso de Terapia Ocupacional da Universidade Federal de Santa Maria (UFSM) sobre as necessidades e desejos manifestados pelas próprias crianças.

Acompanhando o roteiro metodológico, surgiram requerimentos de projeto que direcionaram a geração de alternativas para possíveis produtos, resultando na criação de um carrinho que além de acomodar a criança e o soro/medicamento necessário para o tratamento, possa ser utilizado dentro do hospital, evidentemente, procurando obedecer às normas de higienização e segurança necessárias para seu funcionamento, mas também e não menos importante, oportunizar ao paciente passear pelo hospital e possa praticar atividades, como desenho, pintura, jogos. O projeto, portanto, fundamenta-se na fusão de um suporte para soro/medicamento e um carrinho que permita a movimentação da criança enquanto é submetida ao tratamento quimioterápico, tornando mais divertida sua estadia e auxiliando no desvio do foco na doença e hospitalização para atividades que provoquem contentamento (Figuras 4). $16^{\circ}$ Ergodesign - Congresso Internacional de Ergonomia e Usabilidade de Interfaces Humano Tecnológica: Produto, Informações Ambientes Construídos e Transporte

$16^{\circ}$ USIHC - Congresso Internacional de Ergonomia e Usabilidade de Interfaces Humano Computador

CINAHPA | 2017 - Congresso Internacional de Ambientes Hipermídia para Aprendizagem.
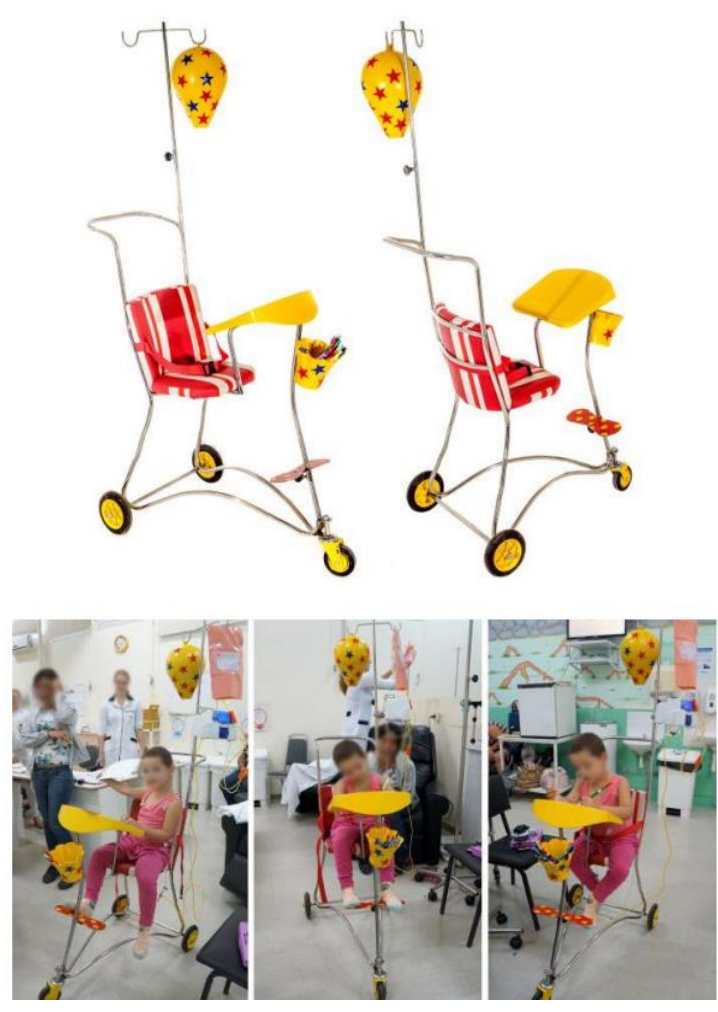

Figura 4: Carrinho Circo em uso. Fonte: Autores.

A partir do financiamento do convênio edital do COMDICA (Conselho Municipal da Criança e do Adolescente de Santa Maria) do ano de2015, foram produzidos seis exemplares do Circo.

Posteriormente foram doados para a utilização dos pacientes em atendimento de diferentes setores do Hospital Universitário da UFSM(Figura 5). 



Figura 5: Exemplares do Carrinho Circo sendo doados. Fonte: Autores.

\subsubsection{MESA MIMO}

Esse trabalho desenvolveu-se no Centro de Tratamento da Criança e do Adolescente com Câncer (CTCriaC), localizado no Hospital Universitário de Santa Maria (HUSM), dentro do campus da Universidade Federal de Santa Maria (UFSM), em parceria com a terapia ocupacional, com intuito de levar o design para dentro do hospital projetando um produto adequado para o meio hospitalar para a utilização pelos pacientes que vivenciam a internação, auxiliando em suas atividades diárias e relacionamento com $\mathrm{o}$ ambiente em que estão acomodados.

Como produto final foi desenvolvido um suporte para múltiplas atividades que se assemelha a uma mesinha, podendo ser utilizado para estudar, ler, brincar, desenhar, comer, apoio para notebooks, entre outros (Figuras 5). $16^{\circ}$ Ergodesign - Congresso Internacional de Ergonomia e Usabilidade de Interfaces Humano Tecnológica: Produto, Informações Ambientes Construídos e Transporte

$16^{\circ}$ USIHC - Congresso Internacional de Ergonomia e Usabilidade de Interfaces Humano Computador

CINAHPA | 2017 - Congresso Internacional de Ambientes Hipermídia para Aprendizagem.
Na mesinha as hastes são retráteis e de fácil manuseio, o tampo possui um encaixe para folhas de atividades ilustradas que se dá a partir de prendedores na parte interna para segurar as páginas e conta com uma tela transparente para que os usuários possam riscar e limpar com facilidade, descartando também o uso do papel - que não é muito aconselhado dentro de unidades de internação.

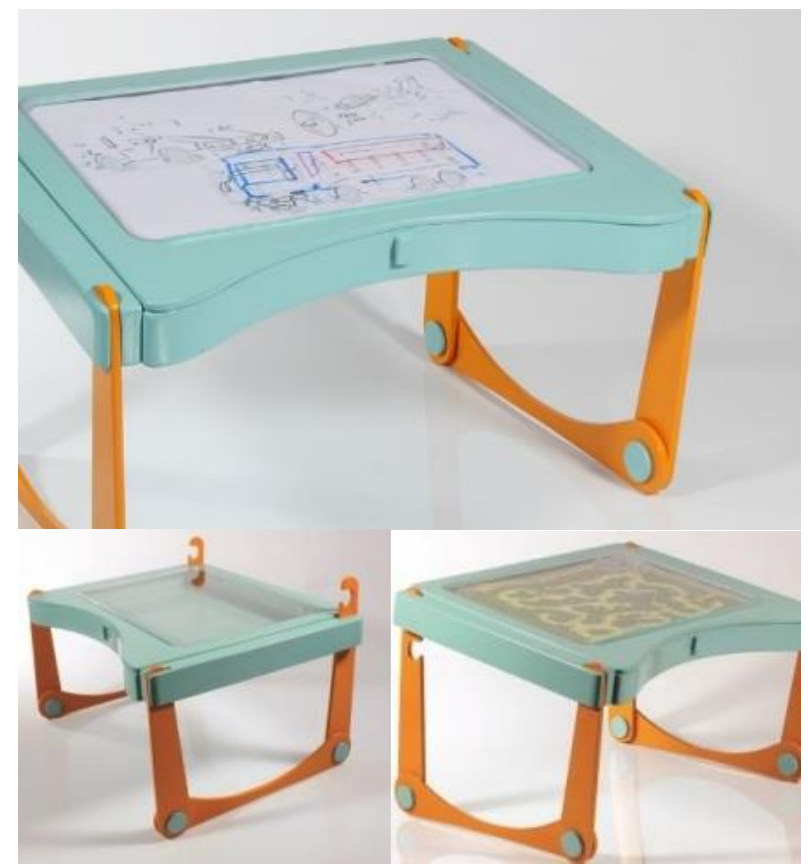

Figura 6: Detalhes da mesa Mimo. Fonte: Autores.

Outra grande preocupação era o fluxo do hospital que deve estar sempre funcionando para melhor atender ao paciente, não podendo, portanto, conter objetos obstruindo o caminho dentro dos quartos, caso haja a necessidade de deslocamento de equipamentos ou trânsito de médicos e demais funcionários. Para que o produto não atrapalhe na rotina do hospital, na parte traseira existem encaixes para ganchos, assim, quando não estiver sendo utilizada a mesa poderá virar um quadro, podendo expor desenhos das crianças, informativos sobre o hospital, recados, etc. Possui também a possibilidade de ser guardado, sendo desmontável, e para que nada ocupe espaço no hospital as canetas, jogos e hastes da mesa podem ser guardados em seu interior, evitando transtornos e perdas de material. A possibilidade de 


\section{$16^{\circ}$ \\ ERGODESIGN USIHC CINAHPA}

armazenamento também auxilia caso o objeto necessite ser transportado.

Com o mesmo convênio que permitiu a produção dos Carrinhos Circo foram produzidos exemplares da Mesa Mimo. De semelhante modo estes foram posteriormente foram doados para a utilização os pacientes em atendimento de diferentes setores do Hospital Universitário da UFSM (Figura 7 e Figura 8).

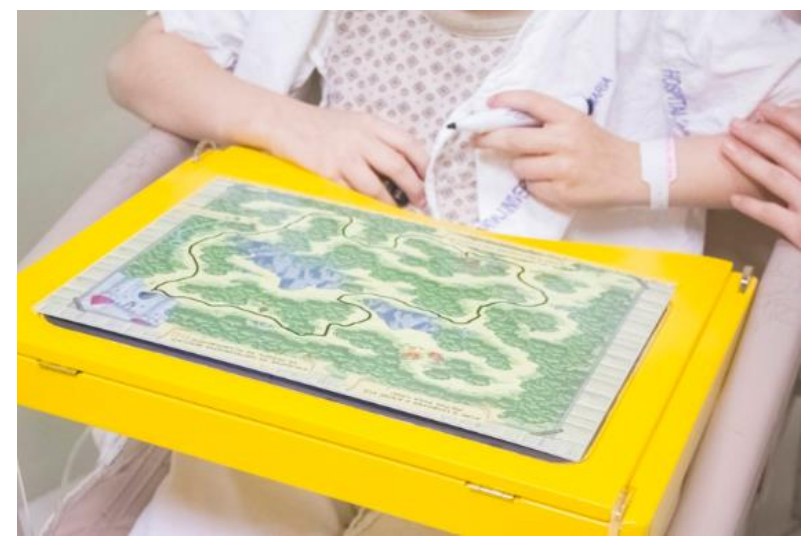

Figura 7: Mesa Mimo em uso. Fonte: Autores.

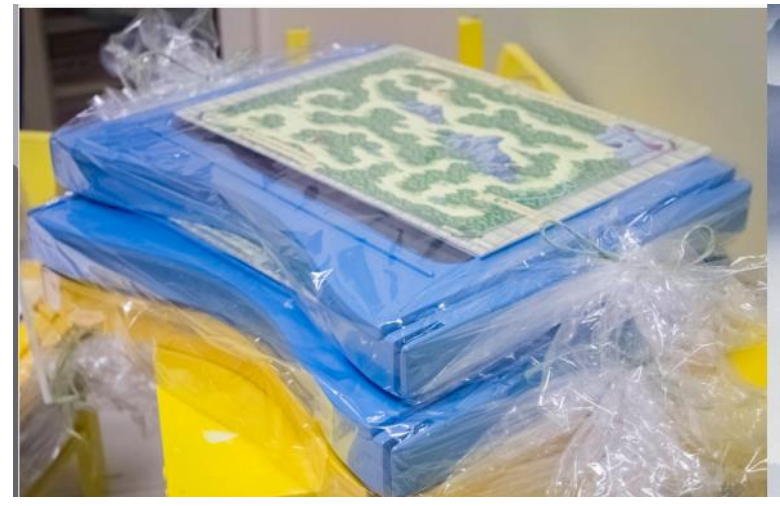

Figura 8: Exemplares da mesa Mimo sendo doados a equipe de atendimento do CT Criac. Fonte: Autores.

\section{Considerações Finais}

Ao observar o desenvolvimento de produtos a partir das experiências vivenciadas em projetos desenvolvidos com base em parceria de diferentes profissionais constata-se a importância da associação dos saberes entre as diversas áreas de conhecimento. O papel do desenhista, no presente $16^{\circ}$ Ergodesign - Congresso Internacional de Ergonomia e Usabilidade de Interfaces Humano Tecnológica: Produto, Informações Ambientes Construídos e Transporte

$16^{\circ}$ USIHC - Congresso Internacional de Ergonomia e Usabilidade de Interfaces Humano Computador

CINAHPA | 2017 - Congresso Internacional de Ambientes Hipermídia para Aprendizagem.

relato, é estendido ao passo que o terapeuta participa do processo de desenvolvimento do produto visto a importância da resolução das necessidades do usuário.

As necessidades do usuário, por sua vez, são clarificadas a medida que o profissional da terapia ocupacional integra a equipe de projeto, onde ocorre a ênfase no projeto de produtos que evidenciem maior qualidade de vida nas atividades cotidianas. Para as crianças, os resultados registrados através de produtos de caráter lúdico, adequados as suas especificidades e que trazem estímulos aos seus sentidos caracteriza como importante avanço em produtos do setor infantil e de brinquedos.

Não se pode mensurar os relevantes cruzamentos interdisciplinares entre ambas as áreas abordadas no presente artigo. Ressalta-se a importância do desenvolvimento de projetos que evidenciem relações de diferentes áreas, em diferentes produtos bem como a busca por demandas reais existentes na comunidade local.

\section{BIBLIOGRAFIA}

ELKONIN, D. B. Psicología del juego. Madrid, Gráficas Valencia S. A. Los Barrios, I. Pol. Ind. Cabo Callego. Fuenlabrada, 1985

FREUD, Sigmund. Obras psicológicas completas de Sigmund Freud, volume XVIII- Além do princípio do prazer, psicologia de grupo e outros trabalhos. Rio de Janeiro: Imago Editora, 1969.

GOMES FILHO, J. Design do objeto: bases conceituais.São Paulo: Escrituras Editora, 2006.

HAGEDORN, R. Fundamentos para a prática em Terapia Ocupacional: uma abordagem estruturada aos conhecimentos e processos centrais. São Paulo: ROCCA, 2008.

HESKETT, John. Desenho industrial. Rio de Janeiro: José Olympio, 1998.

KUDO, Aide Mitie et al. (coord.). Fisioterapia, fonoaudiologia e terapia ocupacional em 


\section{$16^{\circ}$ \\ ERGODESIGN USIHC CINAHPA}

$16^{\circ}$ Ergodesign - Congresso Internacional de Ergonomia e Usabilidade de Interfaces Humano Tecnológica: Produto, Informações Ambientes Construídos e Transporte

$16^{\circ}$ USIHC - Congresso Internacional de Ergonomia e Usabilidade de Interfaces Humano Computador

CINAHPA | 2017 - Congresso Internacional de Ambientes Hipermídia para Aprendizagem.

pediatria. São Paulo: Sarvier, 1994

ROZA, E. S.; REIS, E. S. Da análise na infância ao infantil na análise. Rio de Janeiro: Contra Capa, 1997.

\section{VYGOTSKY, Lev S. A formação social da} mente. Porto alegre: Martins Fontes, 1989.

WINNICOTT, D. W. O brincar e a realidade. Rio de Janeiro: Imago, 1975.

\section{AGRADECIMENTOS}

A todos os acadêmicos, professores, profissionais, pacientes, familiares e voluntários envolvidos no projeto. 